\title{
Extra-intestinal pathogenic Escherichia coli - threat connected with food-borne infections
}

\author{
Bernard Wasiński ${ }^{1, A-F} \oplus$ \\ ${ }^{1}$ Department of Microbiology, National Veterinary Research Institute, Puławy, Poland \\ A - Research concept and design, B - Collection and/or assembly of data, C - Data analysis and interpretation, \\ $D$ - Writing the article, $E$ - Critical revision of the article, $F$ - Final approval of article
}

Wasiński B. Extra-intestinal pathogenic Escherichia coli - threat connected with food-borne infections. Ann Agric Environ Med. 2019; 26(4): 532-537. doi: 10.26444/aaem/111724

\begin{abstract}
Infections caused by extra-intestinal pathogenic Escherichia coli (ExPEC) are a serious public health problem worldwide. The most troublesome are urinary tract infections, severe neonatal meningitis, serious intraabdominal infections, and more rarely, pneumonia, intravascular-device infections, osteomyelitis, soft-tissue infections or sometimes bacteraemia. These strains are also able cause significant economic losses in animal husbandry. A thorough understanding of ExPEC ecology, reservoirs, chains and dynamics of transmission can greatly contribute to a reduction in the burden of ExPEC-associated disease. The ability of $E$. coli (including ExPEC) to exist and survive in various ecological niches impedes the precise recognition and indication of transmission routes most important for individual infections cases. Among many identified ExPEC reservoirs, animal companion and animals providing food seem to be important sources of infection for human; however, the real level of risk connected with potential transmission of these bacteria remains unclear. Food is indicated as one of potential ways of transmission. Despite a quite high number of reports, many of the uncertainties are expected to be reliably elucidated. This review presents most important data on the current state of knowledge concerning the potential role of food in ExPEC transmission. The possible consequences of ExPEC infections in human and animals are briefly described.
\end{abstract}

Key words

food, food-borne pathogens, extra-intestinal pathogenic escherichia coli, ExPEC

\section{INTRODUCTION}

Extra-intestinal pathogenic Escherichia coli (ExPEC), recognized recently as the most common Gram-negative pathogen in humans [1], is a widely diverse E. coli pathotype able to colonize various, often highly specialized, and ecological niches [2]. The facultative pathogen strains can reside in the gastro-intestinal tract where they usually do not cause disease $[3,4]$. Outside the gastro-intestinal tract, however, they can cause infections of tissues or organs vulnerable to the virulence factors possessed by colonizing strains $[2,4]$.

The most important features differentiating the ExPEC from commensal and enteric E. coli (helpful also during ExPEC classification) are virulence traits that allow their successful colonization [2]. Among the virulence factors, adhesins (e.g. fimbriae), iron-acquisition systems, capsules and toxins (e.g. haemolysin) are indicated as distinctive traits for ExPEC $[4,5]$. The efforts aimed at defining ExPEC have been based on available methods of phenotyping and genotyping [6]. The earliest classification system based on serological typing uses $\mathrm{O}, \mathrm{H}$ and $\mathrm{K}$ surface antigens [1]. Currently, phylogenetic grouping is a common classification system which enables the distinguishing of E. coli into one of eight groups: A, B1, B2, C, D, E, F and cryptic clade 1 $[7,8]$. The majority of ExPEC are classified into B2 and D phylogroup [4]. Another classification system, based on the multilocus sequence typing (MLST) method, utilizes known sequence variation within a set of housekeeping

Address for correspondence: Bernard Wasiński, National Veterinary Research Institute, Poland

E-mail: wasinski@piwet.pulawy.pl

Received: 01.07.2019; accepted: 10.08.2019; first published: 12.09 .2019 genes to assign a sequence type (ST). For consistency, current nomenclature describes ExPEC strains using combination of Serotype-Phylogroup-Sequence Type, e.g. O15:K52:H1D-ST393 or O11:K52:H18-D-ST69 [4]. Genotyping based on the virulence gene profile is also a commonly used method for classifying E. coli, including ExPEC.

In contrast to enteric E. coli pathotypes, ExPEC can mostly affect some specific subgroups of the population, such as neonates, the elderly or immunocompromised patients [9, 10]. Infections caused by ExPEC are noted in all age groups of humans and animals. In neonates, ExPEC is the leading cause of meningitis. Severe neurological lesions induced by these pathogens lead to the death of $20-40 \%$ of infected newborns [11]. In adults, ExPEC is identified as one of most common causes of urinary tract infections, and less often is recognized as the cause of diverse intraabdominal infections, pneumonia, intravascular-device infections, osteomyelitis, soft-tissue infections among others [5]. The consequence of infection at any of mentioned sites can be bacteremia [5].

Food animals and pets are considered as potential reservoirs of ExPEC; however, some uncertainties and doubts concerning this issue are still emphasized. They arise from problems connected with the precise investigation of the transmission of these pathogens among animals, and their dissemination via food [4]. Infections caused by ExPEC in animals can induce severe losses, e.g. in the poultry industry. Avian pathogenic E. coli (APEC) invading the respiratory tract of poultry cause inflammation of air the sacs, which can lead to the development of septicemia and generalized infection. The losses connected with these outbreaks result from a reduced growth rate, high mortality (even 20\%), and expenses connected with condemnation of carcasses at the slaughterhouse and elsewhere [9]. 
Avian pathogenic E. coli can also cause inflammation of the oviduct (salpimgitis) in laying hens and broiler breeders which can result in reduced egg production and increased embryonic mortality. Another quite frequently described problem among chickens, induced by ExPEC, is cellulites, characterized as a subcutaneous inflammation in the lower abdomen and thigh [12]

In cattle, mastitis belongs to the most important problems for which ExPEC are responsible as one of the etiological agents. Apart from economic losses connected with decreased milk production, sporadic cases of death of cows can occur after peracute course of mastitis. A less common, however annoying, problem caused by ExPEC in cattle are urinary tract infections (UTIs) [9].

In swine, UTIs caused by $E$. coli are a significant cause of death among adult animals [9]. Other burdensome health problems induced partly by ExPEC are, coliform mastitis, arthritis, meningitis and pneumonia $[13,14]$.

In horses, bronchopneumonia associated with extraintestinal-pathogenic E. coli has been described [15]. Cases of haemorrhagic and necrotizing pneumonia induced by ExPEC have also been noted in dogs and cats $[16,17,18,19]$.

The human-to-human transmission of ExPEC has been unambiguously demonstrated by several investigators [20, 21, 22, 23]. Evidence of resembling ExPEC environmental E. coli in domestic animals and various environmental samples suggests multiple non-human reservoirs for human ExPEC. The dissemination of these pathogens along various transmission routes is not called in question; however, the importance of particular routes remains unclear [4]. A number of investigations concerning the food-borne transmission of food animals or retail meat associated ExPEC have been conducted recently in many countries [6]. Although special attention was focused on poultry products $[24,25,26,27$, 28 ], other types of meat were also widely investigated [29, $30,31,32]$. The suspicion concerning the crucial role of food as a reservoir and transmission route of human ExPEC derives, in part, from the confirmed contribution of food in the transmission of enteric E. coli. However, evidences of genetic relationships between APEC and human ExPEC, or evidences of the pathogenic potential of APEC for mammals or human-derived ExPEC for birds [4], additionally support the suspicion.

The aim of this review is the presentation of the current state of knowledge concerning the role of food in ExPEC transmission.

Poultry meat. Suspicions concerning the principal role of poultry retail meat products as a vehicle of ExPEC causing diseases in humans, are based on quite numerous, however still indirect, evidences. Considerable similarity between genomes, virulence factors profiles and antimicrobial resistance patterns of APEC and human ExPEC strains, have been observed by many investigators $[31,33,34,35,36,37,38$, $39,40,41]$. These observations contributed to the emergence of an hypothesis that some human-associated ExPEC evolved from, or are the same as, APEC causing extraintestinal infections in poultry [42]. Recent findings indicate large plasmids of APEC as a potential source of virulence genes for other ExPEC strains [12, 37, 43]. Additional evidences suggesting that the zoonotic potential of APEC originate from experiments demonstrating the pathogenicity of these strains. In one experiment, B2 E. coli isolated from meat and from the intestines of healthy chickens, caused infection in the urine model of human UTI [29]. More recently, B2 E. coli from UTI patients, poultry meat and healthy chickens were shown as being virulent in a mouse model of UTI $[12,44]$. Mellata et al. [45] in their findings established that chickenderived food products contain E. coli strains that, in rodent models of multiple human-associated ExPEC infections, are able to cause disease comparable to human-source $E$. coli clinical isolates, which suggests that they may pose a significant food safety threat.

Research teams investigating the role of retail meat in human ExPEC infections in various countries point to large proportion of chicken meat contaminated with E. coli including often ExPEC strains. The authors from the USA and Canada reported a higher number ExPEC isolations from poultry retail meat versus pork and beef [31, 46, 47]. Research in Sweden identified as belonging to ExPEC, lineages ST69, ST10, and ST117, about 50\% of the extended-spectrum beta-lactamses (ESBL) producing E. coli isolated from retail domestic chicken meat [4]. Considerably high contamination with ExPEC was also found in chicken meat imported into Sweden $[48,49]$. In Finland, the investigation of 291 poultry meat products from retail market indicated the presence of potential ExPEC strains in $22 \%$ of samples [50]. A study conducted in the Czech Republic showed a 23\% prevalence of ExPEC in meat of broilers [51]. Reports showing considerable (however, not always high) levels of ExPEC prevalence in retail chicken meat also come also from Asia, South America and the Middle East [52, 53, 54, 55].

Pork. Retail pork is also mentioned as a potential way of the transfer of ExPEC strains from animals to humans; but not as frequent as poultry meat products. Strains recognized as human ExPEC were found on pig farms [35], in pigs [56] and in retail pork meat $[29,30,31,46,57]$. Some investigators note a possible connection between certain UTI cases in women with frequent pork consumption reported by the patients [30]. A study conducted in Denmark and Norway identified E. coli ST131 among strains isolated from UTI cases and from pork [58]. In another study, ST10 strains were detected among isolates from human clinical samples, from pig faeces and from retail pork $[6,35]$. The porcine isolates, however, are regarded as being less virulent than poultry strains [59], which could be connected with the lower overall numbers of virulent genes found in porcine isolates, compared with those derived from poultry [35].

Beef. Cattle and beef products are regarded as not significant sources of ExPEC [4, 6,60]; however, some authors [61] count ground beef among dangerous meat products. Xia et al. [32] found that $3.4 \%$ of 239 isolates from retail ground beef met the molecular criteria for ExPEC. Schmidt et al. [60], during investigation of $E$. coli isolates collected from 103 strip loins samples, did not find strains presenting virulenceassociated markers of human ExPEC. Nevertheless, in the same study, two of the E. coli isolates obtained from the hides of slaughtered cows were identified as ExPEC [60]. In another study, a single isolate obtained from a cow was similar by PFGE to a human O11/O17/O77:K52:H18-D-ST69 isolate [62]. Brazilian investigators tested ground beef samples $(n=23)$, swabs from grinding machines $(n=23)$ and swabs from the hands of meat handlers collected in 23 butcheries [63]. Among E. coli isolates obtained from ground beef samples, 
three were identified as ExPEC. Additionally, two ExPEC were isolated from swabs from grinding machines.

The mentioned results seem to indicate the presence of ExPEC in more than $10 \%$ of ground beef samples, but because of the relatively low number of tested samples the conclusion concerning as high prevalence of ExPEC in ground beef could be erroneous. The studies conducted on more numerous samples indicated usually lower prevalence of ExPEC in beef. The reason for the limited prevalence of ExPEC in healthy beef cattle is not known [6].

Eggs. The high prevalence of ExPEC in chicken and in poultry meat suggests a potential threat connected with the consumption of eggs. Studies concerning this problem, infrequent until now, showed a low number of egg-source isolates identified as ExPEC. A survey of $108 \mathrm{E}$. coli isolates collected from eggs by investigators from the USA, indicated five (4.8\%) strains qualified molecularly as ExPEC [64]. Pathotypes of two of these isolates were recognized as APEC, one isolate contained traits of neonatal meningitis E. coli (NMEC) and sepsis-associated E. coli (SEPEC), and the remaining two strains did not fit into any pathotype groups. In further investigation [45], four of the mentioned isolates showed in virulence tests in rodent models (mice), comparable lethality to ExPEC isolated from chicken meat.

The low prevalence of ExPEC in eggs, in contrast to chicken meat, is explained as a possible consequence of the washing process which can eliminate most chicken-sources $E$. coli isolates from the egg surface, leaving only those that were resistant to the washing process, thereby possibly favouring non-ExPEC over ExPEC [64].

Milk. The contribution of ExPEC in the etiology of mastitis suggest the role of raw milk as a vector of the mentioned type of germs. To date, very limited data are available to describe this route of transmission; however, some studies provide preliminary information concerning raw milk products. Reports from various countries of Latin America, show the results of surveys involving the prevalence of ExPEC in cheeses traditionally made from unpasteurized milk [65, $66,67]$. Investigators from Mexico surveyed 52 samples of five types of fresh unpasteurized cheese [66]. A total of 31 potentially uropathogenic E. coli (UPEC) were isolated from 15 (29\%) of samples. In Brazil, during a survey of 147 raw milk cheese samples, only two strains carrying ExPEC gens were identified [65]. However, in earlier findings involving a total of 83 cheese samples collected from three provinces, 17 isolates were identified as potential ExPEC [67]. Results of the mentioned studies are incompatible and further investigations are necessary to assess the degree of danger connected with the possible transfer of such strains via milk.

Plants. In spite of traits which facilitate the spread of ExPEC in the environment (e.g. ability for long survival in water) and the confirmed presence of strains resembling ExPEC in soil, the data on the contamination of edible plants by this pathotype of E. coli are scant. Available reports usually focus on the general level of contamination caused by E. coli and analysis of the phylogenetic status or virulence potential of isolated strains, rarely regard the virulence factors typical for ExPEC. Nevertheless, a research group from Minnesota in the USA, in addition to meat samples, investigated microbiologically 222 vegetable items and 74 fruit items [25]. The samples were purchased from various retail markets (traditional supermarkets, natural foods markets and farmers' markets). The authors defined ExPEC as $E$. coli strains carrying at least two of the following genes $p a p A$ and/or $p a p C$, sfalfoc, afa/dra, kpsM II, and uitA. During the study, no strains able meet these criteria were found in vegetable and fruit samples [25].

Investigators from Pennsylvania in the USA surveyed 150 samples of leafy greens (50 samples each of lettuce, spinach and kale) [68]. All E. coli isolated from these vegetables (15 isolates from lettuce, 15 from kale and eight from spinach) carried the fim $\mathrm{H}$ gene encoding fimbriae $\mathrm{FimH}$, which enable the binding of bacteria to the uroplakin 1A receptor (UP1a) of bladder epithelial cells [69]. FimH adhesin is typical for UPEC; however, the fimH gene is common in commensal strains of E. coli and other bacteria found in the environment [68]. Next to fim $\mathrm{H}$ gene, one isolate from kale and one from lettuce possessed the ExPEC-associated $h l y D$ gene encoding haemolysin secretion protein $\mathrm{D}$. Moreover, one isolate from spinach, except to $\mathrm{fimH}$, carried the iroN gene encoding siderophore receptor protein [68].

The results described in both mentioned reports seem to indicate a low risk of ExPEC transmission by edible plants; however, for more precise determination of the degree, further investigations are necessary.

\section{CHALLENGES AND DOUBTS}

Many studies considering the possible transmission of ExPEC from animals to humans via food are based on simply finding similarities (e.g. virulence factors or antimicrobial resistance profiles) between animal and human isolates. This can also concern other potential sources of infections. Singer [2] indicates this approach as inadequate for establishing transmission events of ExPEC, and emphasizes the need to quantify the frequency and directionality of these events, and points to particular difficulties in documenting the routes of transmission because of the wide range of potential ExPEC sources (human intestinal tract, animals, food animals, retail meat products, environment, etc.).

Although there are no doubts concerning the potential of ExPEC transfer to humans as a result of the mishandling and/or undercooking of meats, some specific traits of ExPEC infections, e.g. the extended period between gastrointestinal colonization and subsequent extraintestinal infection (up to six months) makes any sound establishment of a source of the infection very challenging [2]. Some studies assume that meat as a source of human ExPEC can lead, for example, to consider comparisons of ExPEC in meat eaters and vegetarians as being unambiguously correct. Partisanship of this comparison relies on the assumption that differences in ExPEC presence in the mentioned two groups can be attributed to the meat consumption only. However, these differences can be additionally connected with many other factors, such as health status, age, hospitalization, etc. [2].

Another challenge is the determination of the directionality of ExPEC transmission. Although most often the unidirectional transfer from animals to human (via, e.g. meat) is considered the important in opposite or bidirectional transfer, as well as human-to-human transmission, the entire complex of environmental dissemination routes should be 
more intensive investigated. In many studies, the restriction of sampling schemes to very few sources forecloses estimation of the possible sources attribution and the real estimation of their importance.

Whole genome sequencing (WGS), used commonly in epidemiological investigations, showed a more than $95 \%$ sequence identity between selected APEC and human ExPEC strains [37]. Despite the high similarity, differences on the level of 5\% could suggest a not recent transmission event [2].

Singer emphasizes, that for analysis of ExPEC isolates collected from multiple sources in a contemporaneous and spatially overlapping sampling frame, a better understanding is needed regarding the expected number of single nucleotide polymorphisms (SNPs) if the isolates were, in fact, transferred from one source to another [2].

A more general problem which still remains unclear is the definition of specific extraintestinal pathotypes of E. coli. Various approaches are used to determine whether a given E. coli isolate is ExPEC. The simplest and widely used, although least reliable approach, is estimation of the clinical context and source of isolation. A more reliable way is characterization of the isolate for phylogenetic background and virulence factor profile. The next, more direct approach, is challenge animals with the isolate in an experimental infection model [70].

Although organisms of particular phylogroups are more or less prone to evolve by acquisition of particular virulence traits, the diversity of ExPEC strains is definitely lower than in the E. coli species as a whole [70].

The ambiguities and data gaps mentioned, as well as needs concerning the improvement of ExPEC study designs, can indicate certain directions for further research. They do not, however, diminish the potential for ExPEC to be transferred to humans via food, especially via meat. The quite complex ecology of ExPEC demands particular diligence during study and sampling design and recognition of the broad range of potential sources and routes of transmission [2]. Improvement of the mentioned elements would enable a scientifically-sound estimation of the importance of food as one route of ExPEC transmission to humans. A precise assessment of the risk connected with this route could be one of the key data during development of the most effective prevention strategy.

\section{REFERENCES}

1. Poolman JT, Wacker M. Extraintestinal pathogenic Escherichia coli, a common human pathogen: challenges for vaccine development and progress in the field. J I D. 2016; 213: 6-13.

2. Singer RS. Urinary tract infections attributed to diverse ExPEC strains in food animals: evidence and data gaps. Front Microbiol. 2015; 6: 28. doi:10.3389/fmicb.2015.00028

3. Dobrindt U, Hacker J. Targeting virulence traits: potential strategies to combat extraintestinal pathogenic E. coli infections. Curr Opin Microbiol. 2008; 11: 409-413.

4. Manges AR. Escherichia coli and urinary tract infections: the role of poultry meat. Clin Microbiol Infect. 2016; 22: 122-129.

5. Russo TA, Johnson JR. Proposal for a new inclusive designation for extraintestinal pathogenic isolates of Escherichia coli: ExPEC. J I D. 2000; 181: 1753-1754.

6. Manges A, Johnson J. Reservoirs of extraintestinal pathogenic Escherichia coli. Microbiol Spectrum 2015; 3(5): UTI-0006-2012. doi:10.1128/microbiolspec.UTI-0006-2012.

7. Markland SM, LeStrange KJ, Sharma M, Kniel KE. Old friends in new places: exploring the role of extraintestinal E. coli in intestinal disease and foodborne illness. Zoonoses and Public Health 2015; 62: 491-496.
8. Clermont O, Christensen JK., Denamur E, Gordon DM. The Clermont Escherichia coli phylo-typing method revised: improvement of specificity and detection of new phylo-groups. Environ Microbiol Rep. 2013; 5: 58-65.

9. Bélanger L, Garenaux A, Harel J, Boulianne M, Nadeau E, Dozois CM. Escherichia coli from animal reservoirs as a potential source of human extraintestinal pathogenic E. coli. FEMS Immuno Med Microbiol. 2011; 62: 1-10.

10. Yamamoto S. Molecular epidemiology of uropathogenic Escherichia coli. J Infect Chemother. 2007; 13: 68-73.

11. Bonacorsi S, Bingen E. Molecular epidemiology of Escherichia coli causing neonatal meningitis. Int J Med Microbiol. 2005; 295: 373-381.

12. Mellata M. Human and avian extraintestinal pathogenic Escherichia coli: infections, zoonotic risk and antibiotic resistance trends. Foodborn Pathogens and Disease 2013; 10: 916-932.

13. Fairbrother JM, Gyles C. Colibacillosis. In: Diseases of swine (2012) $10^{\text {th }}$ edn. Edited by Zimmerman JJ, Karriker LA, Ramirez A, Schwartz KJ and Stevenson GW. (ed.) Ames, Chichester, Oxford: John Wiley \& Sons $723-749$.

14. Tan C, Xu ZA, Zheng H, Liu W, Tang X, Shou J, Wu B, Wang S, Zhao $\mathrm{G}$, Chen $\mathrm{H}$. Genome sequence of porcine extraintestinal pathogenic Escherichia coli strain. J Bacteriol. 2011; 193: 5038.

15. DebRoy C, Roberts EJayarao B, Brooks J. Bronchopneumonia associated with extraintestinal pathogenic Escherichia coli in a horse. J Vet Diagn Invest. 2008; 20: 661-664.

16. Breitschwerdt EB, DebRoy C, Mexas AM, Brown TT, Remich AK. Isolation of necrotoxogenic Escherichia coli from a dog with hemorrhagic pneumonia. J Am Vet Med Assoc. 2005; 226: 2016-2019.

17. Hndt LK, Stoffergen DA, Prescott JS, Pouch WJ, Ngai DT, Anderson CA, Gatto NT, DebRoy C, Fairbrother JM, Motzel SM, Klein HJ. Clinical and microbiologic characterization of hemorrhagic pneumonia due to extraintestinal pathogenic Escherichia coli in four young dogs. Comp Med. 2003; 53: 663-670.

18. Snyder JA, Haugen BJ. Coordinate expression of fimbriae in uropathogenic Escherichia coli. Infect Immun. 2005; 73: 7588-7596.

19. Sura R, Van Kruingen HJ, DebRoy C, Hinckley LS, Greenberg KJ, Gordon Z, French RA. Extraintestinal pathogenic Escherichia coli induced acute necrotizing pneumonia in cats. Zoonoses Public Health 2007; 54: 307-313.

20. Ender PT, Gajana D, Johnston B, Clabots C, Tamarkin FJ, Johnson JR. Transmission of an Extended-Spectrum-Beta-Lactamase-producing Escherichia coli (sequence type ST131) strain between the father and daughter resulting in septic shock and emphysematous pyelonephritis. J Clin Microbiol. 2009; 47: 3780-3782.

21. Foxman B, Zhang L, Tallman P, Andree BC, Geiger AM, Koopman JS, Gillespie BW, Palin KA, Sobel JD, Rode CK, Bloch CA, Marrs CF. Transmission of uropathogens between sex partners. J Infect Dis. 1997; 175: 989-992.

22. Johnson JR, Clabots C. Sharing of virulent Escherichia coli clones among household members of a woman with acute cystitis. Clin Infect Dis. 2006; 43: 101-108.

23. Uleryd P, Sandberg T, Scheutz F, Clabots C, Johnston BD, Thuras P, Johnson JR. Colonization with Escherichia coli strains among female sex partners of men with febrile urinary tract infection. J Clin Microbiol. 2015; 53: 1947-1950.

24. Jakobsen L, Hammerum AM, Frimodt-Møller N. Detection of clonal group A Escherichia coli isolates from broiler chickens, broiler chicken meat, community-dwelling humans, and urinary tract infection (UTI) patients and their virulence in a mouse UTI model. Appl Environ Microbiol. 2010; 76: 8281-8284.

25. Johnson JR, Delavari P, O’Bryan TT, Smith K.E, Tatini S. Contamination of retail foods, particularly turkey, from community markets (Minnesota 1999-2000) with antimicrobial-resistant and extraintestinal pathogenic Escherichia coli. Foodborne Path Dis. 2005; 2: 38-49.

26. Leverstein-van Hall M, Dierikx CM, CohenStuart J, Voets GM, van den Munckhof MP, van Essen-Zandbergen A, Platteel T, Fluit AC, van de Sande-Bruinsma N, Scharinga J, Bonten MJM, Mevius DJ. Dutch patients, retail meat and poultry share the same ESBL genes, plasmids and strains. Clin Microbiol Infect. 2011; 17: 873-880.

27. Overdevest I, Willemsen I, Rijnsburger M, Eustance A, Xu L, Hawkey P.,Heck M, Savelkoul P, Vandenbroucke-Grauls C, van der Zwaluw K, Huijsdens X, Kluytmans J. Extended-spectrum $\beta$-lactamase genes of Escherichia coli in chicken meat and humans, The Netherlands. Emarg Infect Dis. 2011; 17: 1216-1222.

28. Ukah UV, Glass M, Avery B, Daignault D, Mulvey MR, Reid-Smith RJ, Parmley EJ, Portt A, Boerlin P, Manges AR. Risk factors of acquisition of multidrug-resistant Escherichia coli and development 
of community-acquired urinary tract infections. Epidemiol Infect. 2018; 146: 46-57.

29. Jakobsen L, Spangholm DJ, Pedersen K, Jansen LB, Emborg HD, Agersø Y, Aarestrup FM, Hammerum AM, Frimodt-Møller N. Broiler chicken, broiler chicken meat, pigs and pork as sources of ExPEC related virulence genes and resistance in Escherichia coli isolates from community-dwelling humans and UTI patients. Int J Food Microbiol. 2010; 142: 264-272.

30. Manges AR, Smith SP, Lau BJ, Nuval CJ, Eisenberg JN, Dietrich PS, Riley LW. Retail meat consumption and the acquisition of antimicrobial resistant Escherichia coli causing urinary tract infections: a case-control study. Foodborne Pathog Dis. 2007; 4: 419-431.

31. Vincent C, Boerlin P, Diagnault D, Dozois CM, Dutil L, Galanakis C, Reid-Smith RJ, Tellier PP, Tellis PA, Ziebell K, Manges AR. Food reservoir for Escherichia coli causing urinary tract infections. Emerg Infect Dis. 2010; 16: 88-95.

32. Xia X, Meng J, Zhao S, Bodies-Jones S, Gaines S.A, Ayres SL, McDermott $\mathrm{PF}$. Identification of antimicrobial resistance of extraintestinal pathogenic Escherichia coli from retail meat. J Food Protect. 2011; 74: $38-44$.

33. Mora A, Herrera A, Mamani R, López C, Alonso MP, Blanco JE, Blanco M, Dahbi G, García-Garrote F, Pita JM, Coira A, Bernárdez MI, Blanco J. Recent emergence of clonal group O25b:K1:H4-B2-ST131 ibeA strains among Escherichia coli poultry isolates, including CTX-M-9-producing strains, and comparison with clinical human isolates. Appl Environ Microbiol. 2010; 76: 6991-6997.

34. Mora A, Lopez C, Herrera A, Viso S, Mamani R, Dhabi G, Alonso MP, Blanco M, Blanco JE, Blanco J. Emerging avian pathogenic Escherichia coli strains belonging to clonal groups O111:H4-D-ST2085 and O111:H4-D-ST117 with high virulence-gene content and zoonotic potential. Vet Microbiol. 2011; 156: 347-352.

35. Cortés P, Blanc V, Mora A, Dahbi G, Blanco JE, Blanco M, López C, Andreu A, Navarro F, Alonso MP, Bou G, Blanco J, Llagostera M. Isolation and characterization of potentially pathogenic antimicrobialresistant Escherichia coli strains from chicken and pig farms in Spain. Appl Environ Microbiol. 2010; 76: 2799-2805.

36. Johnson TJ, Kariyawasam S, Wannemuehler Y, MangiameleP, Johnson SJ, Doetkott C, Skyberg J, Lynne AM, Johnson JR, Nolan LK. The genome sequence of avian pathogenic Escherichia coli strain O1:K1:H7 shares strong similarities with human extraintestinal pathogenic E. coli genomes. J Bacteriol. 2007; 189: 3228-3236.

37. Johnson TJ, Longue CM, Johnson JR, Kuskowski MA, Sherwood JS, Barnes HJ, DebRoy C, Wannemuehler YM, Obeta-Yasuoka M, Spanjaard L, Nolan LK. Associations between multidrug resistance, plasmid content, and virulence potential among extraintestinal pathogenic and commensal Escherichia coli from human and poultry. Foodborne Pathol. 2012; 9: 37-46.

38. Johnson TJ, Wannemuehler Y, Johnson SJ, Stell AL, Doetkott C, Johnson JR, Kim KS SpanjaaL, Nolan LK. Comparison of extraintestinal pathogenic Escherichia coli strains from human and avian sources reveals mixed subset representing potential zoonotic pathogens. Appl Environ Microbiol. 2008; 74: 7043-7050.

39. Moulin-Schouleur M, Répérant M, Laurent S, Brée A, Mignon-Grasteau S, Germon P, Rasschaert D, Schouler C. Extraintestinal pathogenich Escherichia coli strains of avian and human origin: link between phylogenetic relationship and common virulence patterns. J Clin Microbiol. 2007; 45: 3366-3376.

40. Rodrigues-Siek KE, Giddings CW, Doetkott C, Johnson TJ, Fakhr MK, Nolan LK. Comparison of Escherichia coli isolates implicated in human urinary tract infection and avian colibacillosis. Microbiology 2005; 151: 2097-2110.

41. Tivendale KA, Lounge CM, Kariyawasam S, Jordan D, Hussein A, Li G, Wannemuehler Y, Nolan LK. Avian pathogenic Escherichia coli strains are similar to neonatal meningitis E. coli strains and are able to cause meningitis in the rat model of human disease. Infect. Immun. 2010; 78: 3412-3419.

42. Manges AR, Johnson JR. Food-borne origins of Escherichia coli causing extraintestinal infections. Clin Infect Dis. 2012; 55: 712-719.

43. Olsen RH, Christensen H, Bisgaard M. Comparative genomics of multiple plasmids from APEC associated with clonal outbreaks demonstrates major similarities and identifies several potential vaccinetargets. Vet Microbiol. 2012; 158: 384-393.

44. Jakobsen L, Garneau P, Bruant P, Harel J, Olsen SS, Porsbo LJ, Hammerum AM, Frimodt-Moller N. Is Escherichia coli urinary tract infection a zoonosis? Proof of direct link with production animals and meat. Eur J Clin Microbiol Infect Dis. 2012; 31: 1121-1129.
45. Mellata M, Johnson JR, Curtiss III R. Escherichia coli isolates from commercial chicken meat and eggs cause sepsis, meningitis and urinary tract infection in rodent models of human infections. Zoonoses Public Health 2018; 65: 103-113.

46. Johnson JR, Kuskowski MA, Smith K, O’Bryan TT, Tatini S. Antimicrobial-resistant and extraintestinal pathogenic Escherichia coli in retail foods. J Infect Dis. 2005; 191: 1040-1049.

47. Racicot Bergeron C, Prussing C, Boerlin P, Diagnault D, Dutil L, Reid-Smith RJ, Zhanel GG, Manges AR. Chicken as reservoir for extraintestinal pathogenic Escherichia coli in humans. Canada Emerg Infect Dis. 2012; 18: 415-421.

48. Agersø Y, Jensen JD, Hasman H, Pedersen K. Spread of extended spectrum cephalosporinase-producing Escherichia coli clones and plasmids from parent animals to broilers and to broiler meat in a production without of cephalosporins. Foodborne Pathog Dis. 2014;11: 740-749.

49. Egervanrn M, Borjesson S, Byfors S, Finn M, Kaipe C, Englund S, Lindblad M. Escherichia coli with extended-spectrum beta-lactamases or transferable AmpC $\beta$-lactamases and Salmonella on meat imported into Sewden. Int J Food Microbiol. 2014, 171, 8-14.

50. Lyhs U, Ikonen I, Pohjavirta T, Raninen K, Pärko-Mälelä P, Pelkonen S. Extraintestinal pathogenic Escherichia coli in poultry meat products on the Finnish retail market. Acta Vet Scand. 2012; 16: 54-64.

51. Literak I, Reitschmied T, Bujnakova D, Dolejska M, Cizek A, Bardon J, Pokludova L, Alexa P, Halova D, Jamborova I. Broilers as a source of quinolone-resistant and extraintestinal pathogenic Escherichia coli in the Czech Republic. Microb Drug Resist. 2013; 19: 57-63.

52. Sukkua K, Pomwised R, Rattanachuay P, Khianngam S, Sukhumungoon P. Characterization of extraintestinal pathogenic Escherichia coli from meat in Southern Thailand. Southeast Asian J Trop Med. Public Health 2017, 48, 98-108.

53. Hussain A, Shaik S, Ranjan A, Nandanwar N, Tiwari SK, Majid M, Baddam R, Qureshi IA, Semmler T, Wieler LH, Islam MA, Chakravortty D, Ahmed N. Risk of transmission of antimicrobial resistant Escherichia coli from commercial broiler and free-range retail chicken in India. Front Microbiol. 2017; Nov 13;8:2120. doi:10.3389/fmicb.2017.02120.

54. Kobayashi RKT, Aquino I, Ferreira ALS, Vidotto MC. EcoR phylogenetic analysis and virulence typing of avian pathogenic Escherichia coli strains and Escherichia coli isolates from commercial chicken carcasses in southern Brazil. Foodborne Pathog Dis. 2011; 8: 631-635.

55. Qabajah M, Awwad E, Ashhab Y. Molecular characterization of Escherichia coli from dead broiler with signs of colibacillosis and ready-to-market chicken meat in the West Bank Br Poult Sci. 2014; 55: 422-451.

56. Ding Y, Tang X, Lu P, Wu B, Xu Z, Liu W, Zhang R, Bei W, Chen H, Tan C. Clonal analysis and virulent traits of pathogenic extraintestinal Escherichia coli isolates from swine in China. BMC Vet Res. 2012; 8: 140.

57. Khan SB, Zou G, Cheng Y, Xiao R, Li L, Wu B, Zhou R. Phylogenetic grouping and distribution of virulence genes in Escherichia coli along the production and supply chain of pork around Hubei, China. J Microbiol Immunol Infect. 2017; 50: 382-385.

58. Trobos M, Christensen H, Sunde M, Nordentoft S, Agers $\emptyset$ Y, Simonsen GS, Hammerum AM, Olsen JE. Characterization of sulphonamideresistant Escherichia coli using comparison of sul2 gene sequences and multilocus sequence typing. Microbiology 2009; 155: 831-836.

59. Xia X, Meng J, McDermott PF, Zhao S. Escherichia coli from retail meats carry genes associated with uropathogenic Escherichia coli, but are weekly invasive in human bladder cell culture. J Appl Microbiol. 2011; 110: 1166-1176.

60. Schmidt JW, Agga GE, Bosilevac JM, Brichta-Harhay DM, Shackelford SD, Wang R, Wheeler TL, Arthur TM. Occurrece of antimicrobialresistant Escherichia coli and Salmonella enterica in beef cattle production and processing continuum. Appl Environ Microbiol. 2015; 81: 713-725.

61. Nordstrom L, Liu CM, Price LB. Foodborne urinary tract infections: a new paradigm for antimicrobial-resistant foodborne illness. Front Microbiol. 2013; 4: 29. doi: 10.3389/fmicb.2013.00029.

62. Ramchandai M, Manges AR, DebRoy C, Smith SP, Johnson JR, Riley LW. Possible animal origin of human-associated multidrug-resistant, uropathogenic Escherichia coli. Clin Infect Dis. 2005; 40: 251-257.

63. Santo E, Rodolpho D, Marin JM. Presence of extraintestinal pathogenic Escherichia coli in butcheries in Taquaritinga, SP, Brazil. Brazil J Microbiol. 2007; 38: 591-593.

64. Mitchell NM, Johnson JR, Johnston B, Ourtiss R, Mellata M. Zoonotic potential of Escherichia coli isolates form retail chicken meat products and eggs. Appl Environ Microbiol. 2015; 81: 1177-1187. 
65. Campos de ACLP, Puño-Sarmineto JJ, Medeiros LP, Gazal LES, Maluta RP, Navarro A, Kobayashi RKT, Fagan EP, Nakazato G. Virulence genes and antimicrobial resistance in Escherichia coli from cheese made from unpasteurized milk in Brazil. Foodborne Pathog Dis. 2018; 15: $94-100$.

66. Guzman-Hernandez R, Contreras-Rodriguez A, Hernandez-Velez R, Perez-Martinez I, Lopez-Merino A, Zaidi MB, Estrada-Garcia T. Mexican unpasteurized fresh cheeses are contaminated with Salmonella, non-O157 Shiga toxin producing Escherichia coli and potential uropathogenic E. coli strains: A public health risk. Int. Food Microb. 2016; 237: 10-16.

67. Ribeiro LF, Barbose MM, Pinto FR, Maluta RP, Oliveira MC, de Souza V, de Medeiros MI, Borges LA, do Amaral LA, Fairbrother JM. Antimicrobial resistance and virulence factors of Escherichia coli in cheese made from unpasteurized milk in three cities in Brazil. Foodborne Pathog Dis. 2016; 13: 469-476.
68. Scheinberg JA, Dudley EG, Campbell J, Roberts B, DiMarzio M, DebRoy C, Cutter CN. Prevalence and phylogenetic characterization of Escherichia coli and hygiene indicator bacteria isolated from leafy green produce, beef, and pork obtained from farmers' markets in Pennsylvania. J Food Prot. 2017; 80: 237-244.

69. Sarowska J, Futom-Koloch B, Jama-Kmiecik A, Frej-Madrzak M, Ksiazczyk M, Bugl-Plaskonska G, Choroszy-Krol I. Virulence factors, prevalence and potential transmission of extraintestinal pathogenic Escherichia coli isolated from different sources: recent reports. Gut Pathog. 2019; 11: 10. https://doi.org/10.1186/s13099-019-0290-0

70. Vila J, Sáez-López E, Johnson JR, Römling U, Dobrindt U, Catón R, Giske GC, Naas T, Carattoli A, Martínez-Medina M, Bosch J, Retmar P, Rodríguez-Bano J, BaqueroF, Soto SM. Escherichia coli: an old friend with new tidings. FEMS Microbiol Rev. 2016; 40: 437-463.

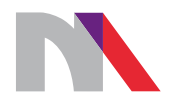

Ministry of Science and Higher Education

Republic of Poland

Generation of the DOI (Digital Object Identifier) - task financed under the agreement No. 618/P-DUN/2019 by the Minister of Science and Higher Education 